\title{
The Spanish version of the Three Factor Eating Questionnaire-R21 for children and adolescents (TFEQ-R21C): Psychometric analysis and relationships with body composition and fitness variables
}

\author{
M. Martín-García a,*, S. Vila-Maldonado a , I. Rodríguez-Gómez a , F.M. Faya a , M. Plaza-Carmona ${ }^{\text {b }}$, \\ J.C. Pastor-Vicedo ${ }^{\mathrm{c}}$, I. Ara ${ }^{\text {a }}$ \\ a GENUD Toledo Research Group, Universidad de Castilla-La Mancha (UCLM), Av. Carlos III, s/n, 45071 Toledo, Spain

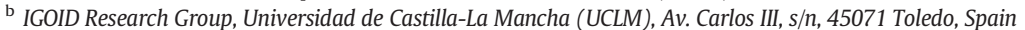 \\ c Faculty of Education, Universidad de Castilla-La Mancha (UCLM), Av. Carlos III, s/n, 45071 Toledo, Spain
}

\section{H I G H L I G H T S}

- TFEQ-R21C is a valid and adapted measure of eating behavior in Spanish youth.

- Cognitive restraint factor is the main eating conduct related to body composition.

- Cognitive restraint and uncontrolled eating factors related to fitness level

- "High fitness + normal-weight status" shows different eating pattern in children.

\section{A R T I C L E I N F O}

\section{Article history:}

Received 16 December 2015

Received in revised form 30 April 2016

Accepted 13 August 2016

Available online 15 August 2016

\section{Keywords:}

Eating behaviors

Children

Physical activity

Body composition

\begin{abstract}
A B S T R A C T
Objective: The main purpose of the present study is to assess the factor structure and reliability of the Spanish version of the 21-item Three Factor Eating Questionnaire (TFEQ-R21C) in children and adolescents and to analyze the relationships between eating behaviors, body composition and cardiovascular fitness.

Subjects: A total of 192 children and adolescents took part in this study ( 89 boys and 103 girls; aged from 8.8 to 16.8 years old and with body mass index (BMI) ranging from 13.2 to $41.1 \mathrm{~kg} / \mathrm{m}^{2}$ ). None of them had either a history of psychological or eating disorders.

Measurements: Body composition (dual-energy X-ray absorptiometry-DXA), anthropometrics (body mass, height and BMI), cardiovascular fitness (cyclo-ergometer incremental test) and eating behaviors (TFEQ-R21C) were determined in all participants.

Results: The confirmatory factor analysis corroborated the same three factors of the original TFEQ-R21: Uncontrolled Eating (UE), Emotional Eating (EE) and Cognitive Restraint (CR). The internal-consistency reliability (Cronbach's alpha coefficient) for the questionnaire was 0.73. Significant differences were found in BMI $\left(F_{2,189}=3.50, p=0.032\right)$ and total fat mass (TFM) $\left(F_{2,189}=3.60, p=0.029\right)$ between tertiles of the CR scale (children who had the lowest scores, also had lower BMI and fat mass). Cardiovascular fitness (measured by relative $\mathrm{VO}_{2}$ peak ) differs depending on the UE and $\mathrm{CR}$ scores. The "healthy" group (those who were normal-weight and had also the highest relative $\mathrm{VO}_{2}$ peak $)$ showed a significant lower $\mathrm{CR}\left(\mathrm{F}_{3,160}=3.07, p=0.030\right)$ and higher UE $\left(F_{3,160}=3.86, p=0.011\right)$ than the "unhealthy" group (those who were neither normal-weight nor had adequate relative $\mathrm{VO}_{2}$ peak).

Conclusions: According to the psychometric analysis of the questionnaire, the TFEQ-R21C is a valid and useful tool to assess eating behaviors in Spanish child population. Further research is necessary to understand the links between eating behaviors and other health-related behaviors such as physical activity time or cardiovascular fitness.
\end{abstract}

(c) 2016 Elsevier Inc. All rights reserved.

\footnotetext{
* Corresponding author at: Department of Physical Activity and Sport Sciences, Universidad Castilla-La Mancha, Avda. Carlos III, s/n, 45071 Toledo, Spain.

E-mail addresses: mariamartingrc@gmail.com (M. Martín-García), sara.vila@uclm.es (S. Vila-Maldonado), irene.rodriguez@uclm.es (I. Rodríguez-Gómez), fatima.faya@uclm.es (F.M. Faya), maria.plazacarmona@gmail.com (M. Plaza-Carmona), juancarlos.pastor@uclm.es (J.C. Pastor-Vicedo), ignacio.ara@uclm.es (I. Ara).
} 


\section{Introduction}

The energy imbalance (inadequate nutritional habits and physical inactivity) is considered to be the main reason for both child and adult obesity [1]. However, the causes of obesity have not been fully explained yet. This energy imbalance, which leads to an increase in body weight, is probably caused by the development of several factors (genetic, socio-cultural or environmental) that make obesity a multi-factorial problem [1].

In the last years, it has been suggested that the obesity epidemic needs a multi-strategic approach, which requires the participation of several areas. The most used strategies to fight against obesity in young people have focused on a single strategy or combined ones such as: physical activity (increasing the number of hours of physical activity or reducing sedentary time), nutrition (reducing caloric intake or avoiding certain foods) and behavioral changes towards a healthier lifestyle [2]. There is no consensus about the most adequate and efficient way to reduce childhood obesity rates. Therefore, studying how each of these elements relates to each other can give us useful information in order to develop the most effective interventions.

In Spain, overweight or obesity prevalence ranges between 31 and $44 \%$ in 6-9 year-old children [3], however, there is a need for valid and usable instruments in order to evaluate each mentioned factor that contributes to excess body weight. Despite the fact that valid instruments to measure physical activity [4] or energy intake [5] exist, not many tools to assess the cognitive-behavioral nature of food intake [6], and more specifically attitudes towards food (eating behaviors), can be found in Spanish children and adolescents.

In this regard, the Three Factor Eating Questionnaire (TFEQ) [7] is one of the most used tools to assess eating behaviors in different populations [8-10]. Recently, Cappelleri et al. [11] have developed a 21-item questionnaire that evaluates eating behavior through three factors. These factors measure cognitive, behavioral and emotional aspects in human eating attitudes: "Cognitive Restraint" (CR), understood as individuals' conscious efforts to control what they eat in order to keep or lose weight; "Uncontrolled eating" (UE), which expresses the tendency to eat excessively in response to the loss of control over the food itself; and "Emotional eating" (EE), understood as the need to overeat when individuals are unable to cope with emotionally negative situations and moods. This TFEQ-R21 version has been tested in young and adult samples [11-14], but up to date it has not been adapted specifically to child population.

In relation to weight status and eating behaviors, the research highlights that cognitive or restrained eating is positively related to body weight and body mass index (BMI) in children and adolescents whether it is measured using the TFEQ $[10,15,16]$ or the Dutch Eating Behavior Questionnaire [17]. However, emotional and external/uncontrolled eating has not such a clear relationship with overweight in children [18]. Moreover, there are few and inconsistent data about the effects of physical activity on appetite in children. Recently, a study found that children who considered possessing a poor-fair physical fitness had higher scores in CR, UE and EE [14]. However, to the best of our knowledge, there is no data about the relationship between an objective measurement of cardiovascular fitness level and eating behavior in young population.

The purpose of the present study is to validate the Spanish version of the TFEQ-R21, specially adapted to children and adolescents, to allow researchers to assess eating behaviors in this population. More specifically, the first aim was to analyze the psychometric properties and factor structure of our Spanish version of TFEQ-R21 for children and adolescents (TFEQ-R21C). The second objective was to examine the connections between eating behaviors, measured through the factors of the questionnaire, and body composition and cardiovascular levels. Finally, the study has analyzed possible gender, age and pubertal development differences.

\section{Methods}

\subsection{Study population}

A total of 192 children and adolescents took part in this study. The sample included 89 boys and 103 girls. The age of the participants ranged from 8.8 to 16.8 years old (mean of $11.8 \pm 1.9$ years old), and their BMI from 13.2 to $41.1 \mathrm{~kg} / \mathrm{m}^{2}$ (mean of $24.4 \pm 5.8 \mathrm{~kg} / \mathrm{m}^{2}$ ). None of them had either a history of psychological or eating disorders. The subjects were recruited from San Juan Bautista School (36.5\%) and Virgen de la Salud Hospital in Toledo (23.4\%) and Severo Ochoa Hospital in Leganés (40.1\%) (both in Spain). Children referred from hospitals included those who were regularly monitored by physicians to assess the evolution of their overweight or obesity status.

Both parents and children were informed about the aims and procedures of the study, as well as the possible risks and benefits. Children gave their verbal assent and written informed consent was obtained from their parents. The study was performed in accordance with the Declaration of Helsinki of 1975 regarding the ethical principles for medical research involving human subjects, being approved by the Ethical Committee of Clinical Research (CEIC 10/10). Data collection was taken between April-July 2014.

\subsection{Validation process of TFEQ-R21C}

The TFEQ-R21C (see Appendix 1), the adapted Spanish version of TFEQ-R21 for children and adolescents, was achieved after the following steps:

1) Translation and back translation procedure by two independent Spanish native speakers who are fluent in English.

2) Back translation review and harmonization between the new translation and the source version.

3) A group of experts in childhood nutrition reviewed the translation and adapted the vocabulary to be understandable for children.

4) A pilot study was done with a small group of respondents $(n=15)$ with similar characteristics to the studied sample (9-17 years), and similar in size to previous studies $[19,20]$. They were asked to make verbal comments in order to verify their understanding of the content of the questionnaire.

5) Review of comments from the pilot study and design of the final version of the questionnaire (TFEQ-R21C).

The final version of the TFEQ-R21C maintains the same number of questions (21 items), the 4-point response scale for answering from the item 1 to item 20 and a 8-point response scale for the item 21, the factors (CR, UE and EE) and the codification of the results proposed by Cappelleri et al. [11].

\subsection{Experimental design}

All children arrived at the laboratory in a fasted state in the morning. After body composition and incremental exercise tests were done, all participants had a standardized breakfast and TFEQ-R21C was distributed among them. Each participant received verbal and written instructions about how to complete it. Children and adolescents answered the questions by themselves, in presence of a professional that helped to solve any doubt that they could have. The TFEQ-R21C required between 10 and $15 \mathrm{~min}$ to be completed. Finally, they completed a self-assessment of the Tanner test in order to register their pubertal development. Participants were divided into pre-pubertal (Tanner status $\leq$ II) and pubertal (Tanner status $\geq$ III) groups. In addition, children and adolescents answered a medical and a general questionnaire that included information regarding the number of hours of physical activity per week ("Do you regularly practice physical activity (at least 2 or 3 times per week)" and "Which sport/activity? (including hours per week and years of this sport/activity)"), if they were on a diet or not, 
medication and any known diseases. None of the participants were doing a food restriction diet nor were they taking any medication that could bias the study. Subjects were asked to avoid strenuous exercise the day before the test and to come to the laboratory in the morning after an overnight fast.

\subsection{Body composition variables}

Body mass (BM) and height were obtained on each child using calibrated balance and stadiometer (SECA Ltd., Hamburg, Germany). Both assessments were undertaken with children in underwear and barefoot. BMI was calculated as BM $(\mathrm{kg})$ divided by height $(\mathrm{m})$ squared.

Dual-energy X-ray absorptiometry (DXA) was used to measure the body composition (Hologic, Serie Discovery QDR, Bedford, USA). Nowadays, DXA is a reference technique for the assessment of body composition in children [21]. All DXA scan tests were analyzed using the software Physician's Viewer, APEX System Software Version 3.1.2. (Bedford, USA). Whole-body scans were made in a supine position, in which children were scanned wearing light clothing with no metal and no shoes or jewelry.

\subsection{Cardiovascular assessment}

The peak oxygen uptake $\left(\mathrm{VO}_{2}\right.$ peak $)$ was determined with indirect calorimetry by using an incremental exercise test to volitional exhaustion on a cycloergometer (Ergometrics 800, Ergoline, Germany). Before the graded test, participants received instructions about the exercise protocol and the use of the Borg 6-20 rating of perceived exertion scale. The subjects were instructed to maintain a pedal rate between 60 and 70 revolutions per minute. In addition, they were able to practice breathing into the mask and cycling at a low wattage to familiarize themselves with the cycle ergometer before the test started.

The initial workload of the test varied according to the weight of the participants (12.5 W when their weight was lower than $30 \mathrm{~kg}$ and $25 \mathrm{~W}$ when it was higher), followed by $12.5 \mathrm{~W}$ gradual increases every $3 \mathrm{~min}$ until respiratory exchange ratio was $\geq 1.0$. After that point, the workload was increased by $12.5 \mathrm{~W}$ every minute until volitional fatigue. Children were encouraged by researchers throughout the test to perform a maximal effort. In spite of that, some children did not achieve the criteria to consider their test a maximal effort test. Peak effort was defined as the achievement of at least two of the following criteria at the end of the test: 1 ) peak heart rate was $>95 \%$ of age-predicted maximum (210age); 2 ) respiratory exchange ratio $\geq 1.00 ; 3$ ) a perception of effort $\geq 17$ (Borg's scale). During the experiment, gas exchange and heart rate were measured continuously with an $\mathrm{O}_{2}$ and $\mathrm{CO}_{2}$ analyzer (Oxycon Pro, Jaeger, Hoechberg, Germany) and a heart rate monitor (Polar FT7, Polar, Kempele, Finland), respectively. $\mathrm{VO}_{2}$ peak was the highest 10 -second value achieved during the test.

\subsection{Statistical analysis}

Statistical analyses were completed using SPPS v17 (SPSS Inc., Chicago, IL, USA). Before the exploratory factor analysis, we carried out the Kaiser-Meyer-Olkin measure of sampling adequacy and the Bartlett's test of sphericity in order to confirm the suitability of this data for parametric factor analysis. The psychometric analysis of the questionnaire was carried out using the maximum likelihood method with Varimax rotation.

The score of each of the three factors in the questionnaire was divided into tertiles and the respondents were classified into "low", "medium" or "high" groups according to their relative position in each scale (Table 1 ). The results related to cardiovascular fitness are always expressed through the relative $\mathrm{VO}_{2}$ peak $\left(\mathrm{VO}_{2}\right.$ peak in $\left.\mathrm{ml} / \mathrm{kg} / \mathrm{min}\right)$ to compare the participants independently of their weight condition. In order to investigate the relative importance of being a normal-weight child and/or having a high fitness level in eating behaviors, we divided the sample into four different groups: the "healthy" group, those who were normal-weight according to their BMI status [22] and had the highest relative $\mathrm{VO}_{2}$ peak (first tertile); the "only normal-weight" group, those who were normal-weight but their relative $\mathrm{VO}_{2}$ peak was not the highest; the "only fit" group, those who were not normalweight but had the highest relative $\mathrm{VO}_{2}$ peak (first tertile); and the "unhealthy" group, those who were not normal-weight and had not the highest relative $\mathrm{VO}_{2}$ peak.

The relationships between the TFEQ-R21C scores and the variables of the study were examined with one-way ANOVAs. Bonferroni's posthoc tests were used when the Levene's test of homogeneity of variance was not significantly different and Tamhane's post-hoc tests when it was. To determine whether $\mathrm{CR}$, UE and EE were associated with body composition and cardiovascular variables, a series of Pearson correlations were performed. For all statistical analyses, the level of significance was set at $\alpha=0.05$.

\section{Results}

\subsection{Factor structure of the TFEQ-R21C}

The Kaiser-Meyer-Olkin index was 0.82 and the Bartlett's test was $\chi 2=1077.94(p<0.001)$, which confirms the applicability of the parametric factor analysis in this study. According to the maximum likelihood analysis with Varimax rotation performed, the original factor structure of the TFEQ-R21 was replicated in our study. An exploratory analysis identified three factors with an eigenvalue above 1 . The confirmatory factor analysis revealed that each of the 21 items loaded positively to one of the three factors that corresponded to the same factors of the original TFEQ-R21: UE (items 3, 6, 8, 9, 12, 13, 15, 19 and 20), EE (items 2, 4, 7, 10, 14 and 16) and CR (items 1, 5, 11, 17, 18 and 21). These three factors explained $34.44 \%$ of the total variance (Table 2 ).

\subsection{Internal consistency analysis}

Internal-consistency reliability (Cronbach's alpha coefficient) for the questionnaire was 0.73 in this study. Individually, the corresponding values for the UE and EE scales were high, 0.81 and 0.77 respectively, while the CR scale was $\alpha=0.68$. The convergent validity and discriminant validity were analyzed using Pearson correlations. The correlations between items in the same factor were all significant $(p \leq 0.01)$ and in a range from 0.34 to 0.54 , except for one item in the CR factor $(r=0.29)$. Item-scale correlations were all significant $(p \leq 0.01)$ and equal or higher than $r=0.55$. Correlations between items assigned to a determined scale (e.g. CR) and the other 2 scales were low $(r<0.35)$. Additionally, the strongest correlation of each item was found with the scale assigned, meeting the criteria for item-discriminant validity (UE: $r=0.57-0.69$; CR: $r=0.55-0.72$; EE: $r=0.59-0.76)$. The dimension of UE correlated with CR $(r=-0.32 ; p \leq 0.001)$ and with EE $(r=$ $0.47, p \leq 0.001$ ). Thus, all items (except one in the CR scale) met the criteria for both convergent and discriminant validity.

Table 1

Average scores in the "low", "medium" and "high" groups of each eating behavior (mean $\pm \mathrm{SD})$.

\begin{tabular}{llllllllll}
\hline Score & \multicolumn{2}{c}{ “Low" group } & \multicolumn{5}{c}{ “Medium" group } & \multicolumn{3}{c}{ “High" group } \\
\hline UE factor & $1.47^{*}, \#$ & \pm & 0.24 & $2.12^{\dagger}$ & \pm & 0.15 & 2.87 & \pm & 0.40 \\
CR factor & $1.97^{*}, \#$ & \pm & 0.32 & $2.66^{\dagger}$ & \pm & 0.13 & 3.27 & \pm & 0.24 \\
EE factor & $1.05^{*}, \#$ & \pm & 0.08 & $1.40^{\dagger}$ & \pm & 0.08 & 2.11 & \pm & 0.41 \\
\hline
\end{tabular}

Abbreviations: UE, Uncontrolled eating; $C R$, Cognitive restraint; EE, Emotional eating.

* Significant differences ( $p \leq 0.05)$ between "low" vs. "medium" group.

\# Significant differences $(p \leq 0.05)$ between "low" vs. "high" group.

† Significant differences $(p \leq 0.05)$ between "medium" vs. "high" group. 
Table 2

Factor loadings of the TFEQ-R21 items and communalities.

\begin{tabular}{|c|c|c|c|c|c|}
\hline Item & Item content & $\begin{array}{l}\text { Uncontrolled } \\
\text { eating }\end{array}$ & $\begin{array}{l}\text { Emotional } \\
\text { eating }\end{array}$ & $\begin{array}{l}\text { Cognitive } \\
\text { restraint }\end{array}$ & Communality \\
\hline 13 & I'm always hungry enough to eat at any time. & 0.60 & & & 0.43 \\
\hline 3 & Sometimes when I start eating, I just can't seem to stop. & 0.60 & & & 0.39 \\
\hline 15 & When I see something that looks very delicious, I often get so hungry that I have to eat right away. & 0.58 & & & 0.32 \\
\hline 8 & I often get so hungry that my stomach feels like a bottomless pit. & 0.56 & & & 0.41 \\
\hline 6 & Being with someone who is eating, often makes me want to also eat. & 0.54 & & & 0.31 \\
\hline 20 & How often do you feel hungry? & 0.51 & & & 0.33 \\
\hline 9 & I'm always so hungry that it's hard for me to stop eating before finishing all of the food on my plate. & 0.49 & & & 0.26 \\
\hline 12 & $\begin{array}{l}\text { When I smell a sizzling steak or see a juicy piece of meat, I find it very difficult to keep from eating even if I've just } \\
\text { finished a meal. }\end{array}$ & 0.47 & & & 0.27 \\
\hline 19 & Do you go on eating binges even though you're not hungry? & 0.43 & & & 0.24 \\
\hline 16 & When I feel depressed, I want to eat. & & 0.76 & & 0.49 \\
\hline 2 & I start to eat when I feel anxious. & & 0.69 & & 0.31 \\
\hline 10 & When I feel lonely, I console myself by eating. & & 0.58 & & 0.39 \\
\hline 4 & When I feel sad, I often eat too much. & & 0.49 & & 0.17 \\
\hline 14 & If I feel nervous, I try to calm down by eating. & & 0.48 & & 0.14 \\
\hline 7 & When I feel tense, I often feel I need to eat. & & 0.41 & & 0.11 \\
\hline 11 & I hold back on how much I eat at meals on purpose to keep from gaining weight. & & & 0.70 & 0.51 \\
\hline 1 & I take small portions on purpose to control my weight. & & & 0.60 & 0.51 \\
\hline 5 & I don't eat some foods because they make me fat. & & & 0.57 & 0.37 \\
\hline 21 & $\begin{array}{l}\text { On a scale from } 1 \text { to } 8 \text {, where } 1 \text { means no restraint in eating (eating whatever you want, whenever you want it) } \\
\text { and } 8 \text { means total restraint (constantly limiting food intake and never "giving in"), what number would you give } \\
\text { yourself? }\end{array}$ & & & 0.41 & 0.26 \\
\hline 17 & When do you avoid "stocking up" on tempting foods? & & & 0.34 & 0.31 \\
\hline 18 & How likely are you to make an effort to eat less than you want? & & & 0.29 & 0.25 \\
\hline \multicolumn{2}{|r|}{ Explained variance } & 14.75 & 11.22 & 8.47 & \\
\hline \multicolumn{2}{|c|}{ Accumulated variance } & 14.75 & 25.97 & 34.44 & \\
\hline
\end{tabular}

\subsection{Relationship between TFEQ-R21C scores and body composition}

The participants' descriptive characteristics (age, anthropometrics and physical fitness) are summarized in Table 3. There were significant differences between groups of UE in BM $\left(\mathrm{F}_{2,189}=3.77, p=0.025\right)$ and total fat mass $(\mathrm{TFM})\left(\mathrm{F}_{2,189}=3.29, p=0.039\right)$. However, after Bonferroni post-hoc, only significant differences were found between the lowest and the highest tertile in BM, showing that the lowest group were heavier than the highest tertile $(65.34 \pm 21.05$ vs $56.43 \pm 21.45 \mathrm{~kg}, p=0.05$, ES $d=0.42$ ). ANOVA test showed significant differences between groups of CR in BMI $\left(\mathrm{F}_{2,189}=3.50, p=\right.$ $0.032)$, TFM $\left(F_{2,189}=3.60, p=0.029\right)$ and \% TFM $\left(F_{2,189}=3.60, p=\right.$ $0.029)$. In all of these variables, the "low" group had lower values compared to the "high" group (BMI: $23.03 \pm 5.91 \mathrm{vs} 25.52 \pm 5.47 \mathrm{~kg} / \mathrm{m}^{2}$, $p=0.05$, ES d =0.44; TFM: $20.02 \pm 11.03$ vs $25.12 \pm 10.80 \mathrm{~kg}, p=$ 0.036 , ES d $=0.47$; \% TFM: $34.42 \pm 9.26$ vs $38.32 \pm 6.48 \%, p=0.019$, $\mathrm{ES} d=0,49)$. No significant differences were found between groups of EE in body composition variables (Fig. 1).

Table 3

Participants' descriptive characteristics (mean \pm SD)

\begin{tabular}{|c|c|c|c|c|c|c|c|c|c|}
\hline \multirow{2}{*}{$\begin{array}{l}\text { Variables } \\
\text { Age (years) }\end{array}$} & \multicolumn{3}{|c|}{$\begin{array}{l}\text { Normal weight } \\
\text { children } \\
(n=54)\end{array}$} & \multicolumn{3}{|c|}{$\begin{array}{l}\text { Overweight } \\
\text { children } \\
(n=51)\end{array}$} & \multicolumn{3}{|c|}{$\begin{array}{l}\text { Obese } \\
\text { children } \\
(n=87)\end{array}$} \\
\hline & $10.8^{*}, \#$ & \pm & 0.9 & 11.9 & \pm & 1.7 & 12.3 & \pm & 2.1 \\
\hline \multirow[t]{2}{*}{ Sex } & \multirow{2}{*}{\multicolumn{3}{|c|}{$\begin{array}{l}26 \text { boys }(48.1 \%) \\
28 \text { girls }(51.9 \%)\end{array}$}} & \multirow{2}{*}{\multicolumn{3}{|c|}{$\begin{array}{l}21 \text { boys }(41.2 \%) \\
30 \text { girls }(58.8 \%)\end{array}$}} & \multirow{2}{*}{\multicolumn{3}{|c|}{$\begin{array}{l}42 \text { boys }(48.3 \%) \\
45 \text { girls }(51.7 \%)\end{array}$}} \\
\hline & & & & & & & & & \\
\hline Tanner status & $1.8^{*}, \#$ & \pm & 0.7 & $2.5^{\dagger}$ & \pm & 1.1 & 3.0 & \pm & 1.2 \\
\hline Body mass (kg) & $35.9^{*}, \#$ & \pm & 6.0 & $58.7^{\dagger}$ & \pm & 12.0 & 75.0 & \pm & 17.9 \\
\hline Height $(\mathrm{cm})$ & $145.4^{*}, \#$ & \pm & 6.9 & 155.1 & \pm & 11.5 & 159.0 & \pm & 12.5 \\
\hline $\operatorname{BMI}\left(\mathrm{kg} / \mathrm{m}^{2}\right)$ & $16.9^{*}, \#$ & \pm & 1.8 & $24.1^{\dagger}$ & \pm & 2.1 & 29.2 & \pm & 3.4 \\
\hline Body fat (\%) & $25.8^{*}$,\# & \pm & 7.0 & $38.1^{\dagger}$ & \pm & 4.3 & 42.0 & \pm & 4.2 \\
\hline $\mathrm{VO}_{2 \text { peak }}(\mathrm{ml} / \mathrm{kg} / \mathrm{min})$ & $44.4^{*}$,\# & \pm & 7.6 & $32.3^{\dagger}$ & \pm & 5.6 & 28.2 & \pm & 4.3 \\
\hline
\end{tabular}

Abbreviations: BMI, body mass index.

* Significant differences $(p \leq 0.05)$ between normal-weight vs. overweight children.

\# Significant differences $(p \leq 0.05)$ between normal-weight vs. obese children.

Significant differences $(p \leq 0.05)$ between overweight vs. obese children.
3.4. Relationship between TFEQ-R21C scores, physical activity and cardiovascular fitness

Relative $\mathrm{VO}_{2}$ peak is significantly different in "low" vs. "high" tertiles in the UE and CR score $\left(F_{2,163}=4.43, p=0.013\right.$ and $F_{2,163}=4.95$, $p=0.008$, respectively). In the UE factor, the "low" tertile presented lower values of relative $\mathrm{VO}_{2}$ peak in comparison to the "high" tertile $(p=0.026$, ES $d=0.54)$ and the "medium" tertile $(p=0.049$, ES $\mathrm{d}=0.44)$. While in the CR factor, the "low" tertile presented higher values in this variable than the "high" tertile $(p=0.007$, ES $\mathrm{d}=0.65)$. The time that children spend in physical activity does not differ among tertiles of UE or CR factor, but it is significantly different between the "low" and the "high" group of the EE factor $\left(\mathrm{F}_{2,186}=3.04, p=0.05\right)$. Bonferroni post-hoc tests revealed that the "low" tertile spent significantly more time per week in physical activity than the "high" tertile $(2.14 \pm 2.38$ vs $1.25 \pm 1.77$ h per week, $p=0.044$, ES $d=0.43)$.

\subsection{Relationship between TFEQ-R21C scores and health}

The ANOVA test showed that only "healthy" children (those who were normal-weight and had the highest relative $\mathrm{VO}_{2}$ peak) had a different eating behavior profile from the "unhealthy" children (those who were neither normal-weight nor had the highest relative $\mathrm{VO}_{2}$ peak ) in the UE and CR factors (UE: $F_{3,160}=3.86, p=0.011$; and CR: $F_{3,160}=$ $3.07, p=0.030$ ). Thus, being only normal weight or having only the highest relative $\mathrm{VO}_{2}$ peak per se was not enough to make the difference with the "unhealthy" children's eating behaviors (Fig. 2).

\subsection{Relationship between TFEQ-R21C scores and pubertal development, sex and age}

There were significant differences between groups of pubertal development in UE factor $(p=0.002$, ES $d=0.45)$. The pre-pubertal group (Tanner I + II) showed a higher score than the other group (Tanner III + IV $+\mathrm{V})$. When the UE score was divided into three tertiles, a tendency $\left(F_{2,189}=2.72, p=0.07\right)$ for lower pubertal development 


\section{Uncontrolled Eating tertiles}

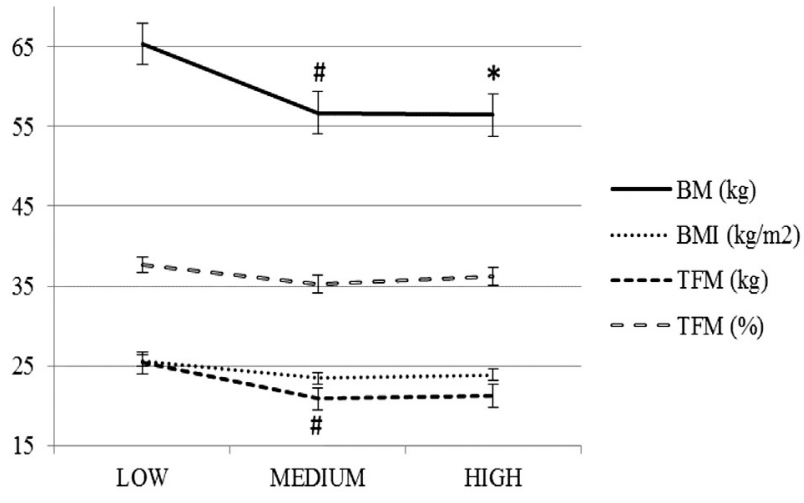

\section{Cognitive Restraint tertiles}

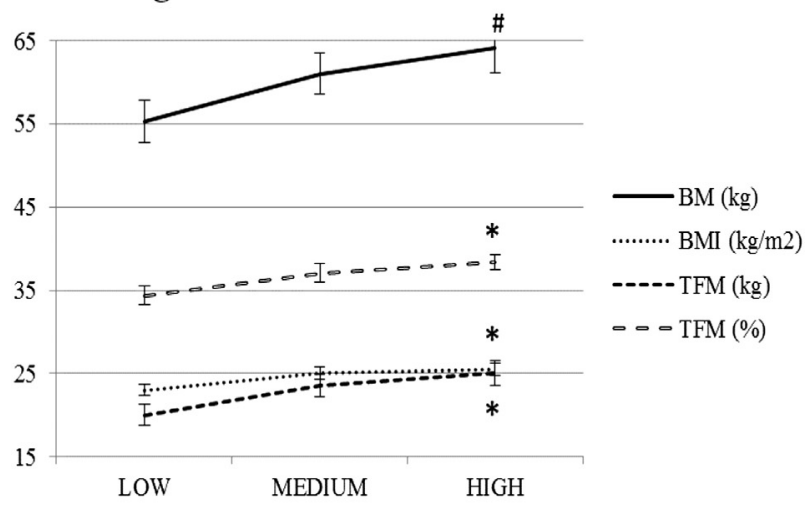

\section{Emotional Eating tertiles}

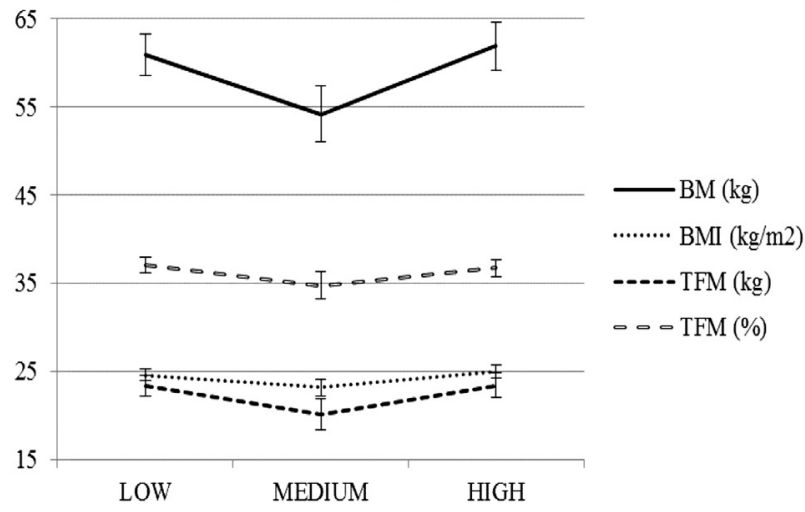

Fig. 1. Relationships between TFEQ-R21C factors and body composition variables. The symbols indicate differences with "low" tertile of the corresponding factor (* means $p \leq 0.050$ and \# means $p=0.070$ ). Abbreviations: BM, body mass; BMI, body mass index, TFM, total fat mass. Data expressed as mean \pm SE to improve its legibility.

was found in children with higher scores in comparison to the lowtertile group. This is supported by a significant correlation between the pubertal development and the UE score $(r=-0.22, p=0.002)$.

Taking into account the whole sample, there were no differences by sex in the scores of the TFEQ-R21C factors. Participants' age is significantly different depending on the UE tertile they belong to $\left(\mathrm{F}_{2,189}=\right.$ $3.86, p=0.023$ ), hence, children's age in the "high" group is significantly lower than in the "low" group of the UE factor $(11.35 \pm 1.79$ vs $12.23 \pm 1.99$ years, $p=0.019$, ES $d=0.47$ ). This data is confirmed by the negative correlation between both variables, age and UE score $(r=-0.23, p=0.001)$.

\section{TFEQ-R21C scores}

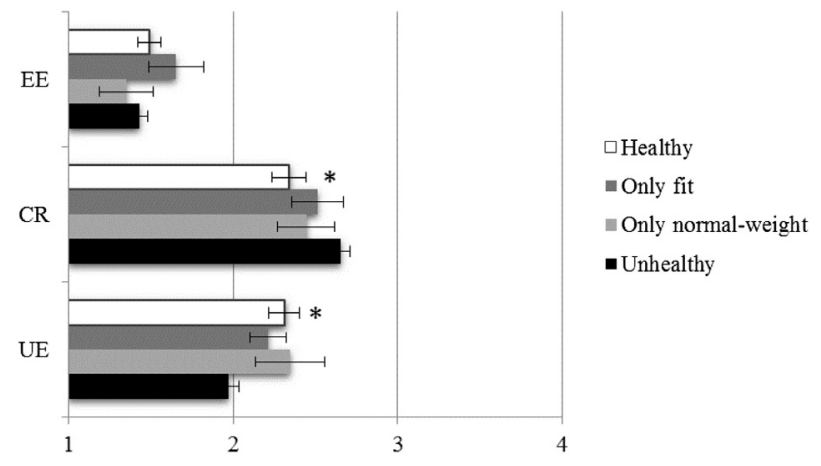

Fig. 2. TFEQ-R21C factors according to the status of health. The asterisks mean significant differences ( $p \leq 0.050)$ between the "healthy" and "unhealthy" groups. Abbreviations: EE, Emotional eating; CR, Cognitive restraint; UE, Uncontrolled eating. Data expressed as mean \pm SE to improve its legibility.

\section{Discussion}

The major findings of this study indicate that the factor structure of the TFEQ-R21 was reproduced in our children and adolescents' adapted version (TFEQ-R21C), showing a good internal consistency. CR behavior was the main factor of the questionnaire related to body composition, supporting previous research [23]. Our results suggest that there is a negative relationship between fitness level and CR score. Moreover, a very interesting finding concerns the combination of both high physical condition and a normal-weight status, which are necessary to find a different pattern in children's eating behaviors.

\subsection{Psychometric analysis of the TFEQ-R21C}

The original TFEQ-R21 was developed in an adult sample and included more than $80 \%$ of women [11]. In our study, it was administered to a child population with different weight status and a $46 \%$ prevalence of boys. The maximum likelihood analysis performed with Varimax rotation managed to reproduce the original factor structure of the TFEQR21 [11] with the same 3 scales: UE (9 items), EE (6 items) and CR (6 items). The internal consistency of the questionnaire and the three factors separately was adequate $(>0.70$, only CR factor had a $\alpha=0.68)$ and similar to previous studies with shortened versions of TFEQ [8-10,24]. Although the Cronbach's alpha had a satisfactory value $(\alpha=0.73)$, it was slightly lower than in other TFEQ validations in which it ranged between 0.81 and 0.85 [14,19,24].

The TFEQ-R21C showed a good internal consistency. Only one item in the CR scale (question 21) had a marginal discrepancy (the correlations with the items in the same factor were lower than expected), while all the rest of the items met the criteria for convergent and discriminant validity. All this data suggests that the TFEQ-R21C is a valid and adapted measure of eating behavior not only for obese children but also for the general child population.

The positive correlation found between external or uncontrolled eating and EE in our study was in line with the significant correlations between the eating behavior factors scores previously reported both using the TFEQ $[10,15]$ and another different eating behavior questionnaire $[17,25]$. It seemed that a considerable overlap between these subscales existed, although from a theoretical point of view they were different [17] and they also showed differences after our psychometric analysis.

\subsection{Body composition and TFEQ-R21C}

Body composition variables showed a stronger relationship with the $\mathrm{CR}$ factor compared to the rest of the factors. Children with higher BMI and fat mass (in $\mathrm{kg}$ and \%) had increased CR scores. This fact was 
confirmed in the whole sample and when participants were split by sex. Consequently, the relationship between CR factor and body composition variables seemed to be stronger than gender differences as previously reported in previous studies [23], indicating that there was a positive connection in which fatter children have a greater restriction about the food that they consume in order to control or lose their weight.

In line with previous studies [14,26], the fact that in our study the "high" CR-tertile had a significantly increased BMI and also a higher fat mass in $\mathrm{kg}$ and percentage (measured by DXA) indicated that BMI can also represent the weight condition (normal-weight, overweight and obese) in the child population. In addition, the CR factor showed its capacity to distinguish among different weight status.

The restraint theory supports that chronic dietary restraint alternates with overeating episodes leading to an increase in weight, this weight gain leads to an increase in the restriction and the latter to put on weight again, becoming a vicious circle $[16,27]$. Thus, in our study it could be expected to find the highest CR and UE scores in children with excess weight. However, our data showed that children who had the lowest UE scores had a higher BM. This was in line with previous findings $[17,25,28]$, which found a negative relationship between external eating and weight status. This could be explained by the fact that maybe overweight or obese participants did not express their real answers in the questions about UE, whereas expressing a high restriction is more socially accepted as a method to control or lose weight.

In our study, the thinnest children, who were also the youngest, had greater UE score. For this reason, we hypothesized that further researches are necessary to confirm whether the UE factor is able to discriminate among varying weights in a sample of similar age or it is an age or pubertal development dependent behavior. It is possible that older participants are more prone to indicate the more desirable answers and this covers up the real evolution of the eating behaviors with the development. In contrast to other studies in adolescents [15], neither BM, BMI nor fat mass were different in relation to a higher or lower EE score.

\subsection{Physical activity, fitness and TFEQ-R21C}

The majority of the studies found in the literature focus on the relationship between either physical activity levels with adiposity or eating behavior and adiposity, but very few have assessed the direct connection between physical activity and eating behavior in children. In this regard, some studies suggest that exercise in adults can improve appetite regulation and emotional eating [29]. In addition, high disinhibition levels and poor eating control have been related to sedentary behavior [30-32]. Moreover, a recent study found that children with poorer perceptions of physical fitness had higher scores in CR, UE and EE [14]. However, to the best of our knowledge, there is no data about the relationship between a measurement of cardiovascular fitness level, such as $\mathrm{VO}_{2}$ peak, and eating behavior. In contrast to previous findings in adults [29-31] and children [14], our data indicated that high scores in the $\mathrm{UE}$ factor were related to higher relative $\mathrm{VO}_{2}$ peak values. Moreover, children with the highest CR scores showed a relative $\mathrm{VO}_{2}$ peak lower than their counterparts in the "low" CR tertile, coinciding with prior findings by Jáuregui-Lobera et al. [14]. Therefore, further studies are needed to clarify the relationship between cardiovascular fitness and eating behaviors in youth population.

\subsection{Health and TFEQ-R21C}

Several studies pointed out that higher cardiorespiratory fitness and/or activity levels are associated with healthier diets in adults [6] and children [33]. Interestingly, Gutin [34] found that children who performed more hours of daily physical activity were those who ingested more calories. It is known that lifestyle factors such as physical activity, sedentary behavior and nutrition do not occur in isolation, but rather they coexist and may reinforce each other [6]. In fact, recent studies focusing on these clustering patterns showed some of the relationships among health-related behaviors in adolescents [35]. As an example, increased physical activity levels seem to lead to tidier hunger-satiety mechanisms [36] and usually a more regulated control of appetite drives to decrease or maintain an adequate BMI [37]. Our results confirmed the idea of the clustering patterns as only the combination of a high fitness level and a normal-weight status (not individually) was sufficient to express a difference in eating behaviors, more specifically in CR and UE conducts.

\section{Limitations and strengths}

To the best of our knowledge, this is the first time that eating behaviors are analyzed in relation to obesity and a cardiovascular fitness measure $\left(\mathrm{VO}_{2}\right.$ peak $)$ in youth population. Although the self-assessment of the physical activity levels must be improved with the implementation of more accurate methods (i.e. accelerometers), the use of a densitometer has enabled us to better confirm the connections between adiposity and eating behaviors previously found in the literature with some less accurate methods.

\section{Conclusions}

In summary, TFEQ-R21C shows a suitable psychometric analysis and a good internal consistency in the Spanish child population studied. Cognitive restraint behavior is strongly related to body composition. Children and adolescents with higher BMI and fat mass showed higher food restriction. Our data suggests that children who scored higher in uncontrolled eating have a higher relative $\mathrm{VO}_{2}$ peak but, on the contrary, those with a higher cognitive restraint score have a lower relative $\mathrm{VO}_{2}$ peak than their counterparts. However, it is necessary to combine both high physical condition and a normal-weight status to find a different pattern in the eating behaviors in this population.

\section{Acknowledgments}

This study was supported by the Consejo Superior de Deportes High Council for Sports (CSD-089/UPB10/11). MMG has received a PhD grant from the Ministerio de Educación, Cultura y Deporte (AP2010-5476). We owe special thanks to Rafael Gracia, Silvia Robledo and Rafael Ibañez from the Department of Sport and Health (Council of Leganés, Madrid); to Dr. Beatriz García Cuartero and Dr. Amparo González Vergaz from the Severo Ochoa Hospital (Leganés, Madrid); and to Dr. Atilano Carcavilla and Dr. Ángel Aragonés from the Virgen de la Salud Hospital (Toledo).

\section{Appendix 1}

The Three Factor Eating Questionnaire - Revised 21-item for Spanish children and adolescents (TFEQ-R21C)

1. Tomo pequeñas cantidades aposta como forma para controlar mi peso.

Muy cierto (4); Bastante cierto (3); Bastante falso (2); Muy falso (1)

2. Empiezo a comer cuando estoy preocupado. Muy cierto (4); Bastante cierto (3); Bastante falso (2); Muy falso (1)

3. A veces, cuando empiezo a comer, parece que no puedo parar. Muy cierto (4); Bastante cierto (3); Bastante falso (2); Muy falso (1)

4. Cuando estoy triste, suelo comer demasiado. Muy cierto (4); Bastante cierto (3); Bastante falso (2); Muy falso (1)

5 . No como algunos alimentos porque me engordan.

Muy cierto (4); Bastante cierto (3); Bastante falso (2); Muy falso (1)

6. Cuando estoy con alguien que está comiendo, a menudo me dan ganas de comer yo también.

Muy cierto (4); Bastante cierto (3); Bastante falso (2); Muy falso (1) 
7. Cuando estoy en tensión, siento la necesidad de comer. Muy cierto (4); Bastante cierto (3); Bastante falso (2); Muy falso (1)

8. Tengo tanta hambre que a menudo mi estómago parece un pozo sin fondo.

Muy cierto (4); Bastante cierto (3); Bastante falso (2); Muy falso (1)

9. Siempre tengo tanta hambre, que a veces es difícil para mí dejar de comer antes de terminar toda la comida del plato.

Muy cierto (4); Bastante cierto (3); Bastante falso (2); Muy falso (1)

10. Cuando me siento solo, me consuelo comiendo.

Muy cierto (4); Bastante cierto (3); Bastante falso (2); Muy falso (1)

11. Intencionadamente como menos en las comidas para no ganar peso. Muy cierto (4); Bastante cierto (3); Bastante falso (2); Muy falso (1)

12. Cuando huelo un filete bien hecho o un jugoso trozo de carne, encuentro muy difícil evitar comer incluso si acabo de terminar de comer.

Muy cierto (4); Bastante cierto (3); Bastante falso (2); Muy falso (1)

13. Siempre tengo tanta hambre como para comer en cualquier momento.

Muy cierto (4); Bastante cierto (3); Bastante falso (2); Muy falso (1)

14. Si estoy nervioso, intento calmarme comiendo.

Muy cierto (4); Bastante cierto (3); Bastante falso (2); Muy falso (1)

15. Cuando veo algo muy rico/delicioso, a menudo me da tanta hambre que tengo que comer de inmediato.

Muy cierto (4); Bastante cierto (3); Bastante falso (2); Muy falso (1)

16. Cuando me siento deprimido, quiero comer. Muy cierto (4); Bastante cierto (3); Bastante falso (2); Muy falso (1)

17. ¿Cuándo evitas comer comidas tentadoras (irresistibles)? Casi nunca (1); Rara vez (2); Algunas veces (3); Casi siempre (4)

18. ¿Qué probabilidades tienes de comer menos de lo que quieres si te lo propones?

Improbable (1); Ligeramente probable (2); Bastante probable (3); Muy probable (4)

19. ¿Continúas comiendo aunque no tengas hambre? Nunca (1); Raramente (2); Algunas veces (3); Al menos una vez a la semana (4)

20. ¿Con qué frecuencia sientes hambre?

Sólo a la hora de comer (1); Algunas veces entre comidas (2); Normalmente entre comidas (3); Casi siempre (4)

21. En una escala del 1 al 8, donde 1 significa "no restricción en la ingesta (comer todo lo que quieras, cuando quieras)" y 8 significa "restricción total (constante limitación de lo que comes y nunca comer todo lo que quieres)", ¿qué número te darías a ti mismo/a? Marca el número del 1 al 8 que mejor se ajuste a lo que tú haces.

1. No restricción en la ingesta (comer todo lo que quieras, cuando quieras).
2.
3.
4.
5.
6.
7.
8. Restricción total (constante limitación de lo que comes y nunca comer todo lo
que quieres).

All answers have been coded as suggested by Cappelleri et al. [11].

\section{References}

[1] E. Atlantis, E.H. Barnes, M.A. Singh, Efficacy of exercise for treating overweight in children and adolescents: a systematic review, Int. J. Obes. 30 (2006) 1027-1040, http://dx.doi.org/10.1038/sj.ijo.0803286.

[2] D. Martinez-Gomez, S. Gomez-Martinez, M.A. Puertollano, E. Nova, J. Wärnberg, O.L. Veiga, et al., Design and evaluation of a treatment programme for Spanish adolescents with overweight and obesity. The EVASYON Study, BMC Public Health 9 (2009) 414, http://dx.doi.org/10.1186/1471-2458-9-414.

[3] N. Pérez-Farinós, A.M. López-Sobaler, M. Dal Re, C. Villar, E. Labrado, T. Robledo, et al., The ALADINO study: a national study of prevalence of overweight and obesity in Spanish children in 2011, Biomed. Res. Int. 2013 (2013) 163687, http://dx.doi. org/10.1155/2013/163687.
[4] M. Laguna, J. Ruiz, M. Lara, S. Aznar, Recommended levels of physical activity to avoid adiposity in Spanish children, Pediatr. Obes. 8 (2013) 62-69, http://dx.doi. org/10.1111/j.2047-6310.2012.00086.x.

[5] L. Serra-Majem, L. Ribas, J. Ngo, R.M. Ortega, A. García, C. Pérez-Rodrigo, et al., Food, youth and the Mediterranean diet in Spain. Development of KIDMED, Mediterranean diet quality index in children and adolescents, Public Health Nutr. 7 (2004) 931-935, http://dx.doi.org/10.1079/PHN2004556.

[6] R.J. Joseph, M. Alonso-Alonso, D.S. Bond, A. Pascual-Leone, G.L. Blackburn, The neurocognitive connection between physical activity and eating behaviour, Obes. Rev. 12 (2011) 800-812, http://dx.doi.org/10.1111/j.1467-789X.2011.00893.x.

[7] A.J. Stunkard, S. Messick, The three-factor eating questionnaire to measure dietary restraint, disinhibition and hunger, J. Psychosom. Res. 29 (1985) 71-83, http://dx. doi.org/10.1016/0022-3999(85)90010-8.

[8] E. Kavazidou, M. Proios, I. Liolios, G. Doganis, K. Petrou, A. Tsatsoulis, et al. Structure validity of the Three-Factor Eating Questionnaire-R18 in Greek population, J. Hum. Sport Exerc. 7 (2012) 218-226, http://dx.doi.org/10.4100/jhse. 2012.71.01.

[9] J. Karlsson, L.O. Persson, L. Sjostrom, M. Sullivan, Psychometric properties and factor structure of the Three-Factor Eating Questionnaire (TFEQ) in obese men and women. Results from the Swedish Obese Subjects (SOS) study, Int. J. Obes. 24 (2000) 1715-1725, http://dx.doi.org/10.1038/sj.ijo.0801442.

[10] B. de Lauzon, M. Romon, V. Deschamps, L. Lafay, J.M. Borys, J. Karlsson, et al., The Three-Factor Eating Questionnaire-R18 is able to distinguish among different eating patterns in a general population, J. Nutr. 134 (2004) 2372-2380.

[11] J.C. Cappelleri, A.G. Bushmakin, R.A. Gerber, N.K. Leidy, C.C. Sexton, M.R. Lowe, et al., Psychometric analysis of the Three-Factor Eating Questionnaire-R21: results from a large diverse sample of obese and non-obese participants, Int. J. Obes. 33 (2009) 611-620, http://dx.doi.org/10.1038/ijo.2009.74.

[12] S. Tholin, F. Rasmussen, P. Tynelius, J. Karlsson, Genetic and environmental influences on eating behavior: the Swedish Young Male Twins Study, Am. J. Clin. Nutr. 81 (2005) 564-569.

[13] K.K. Danielsen, M. Svendsen, S. Maehlum, J. Sundgot-Borgen, Changes in body composition, cardiovascular disease risk factors, and eating behavior after an intensive lifestyle intervention with high volume of physical activity in severely obese subjects: a prospective clinical controlled trial, J. Obes. 2013 (2013) 325464, http:// dx.doi.org/10.1155/2013/325464.

[14] I. Jáuregui-Lobera, P. García-Cruz, R. Carbonero-Carreño, A. Magallares, I. Ruiz-Prieto, Psychometric properties of Spanish version of the Three-Factor Eating Questionnaire-R18 (Tfeq-Sp) and its relationship with some eating-and body image-related variables, Nutrients 6 (2014) 5619-5635, http://dx.doi.org/10. 3390/nu6125619.

[15] O. Megalakaki, M. Mouveaux, M. Hubin-Gayte, L. Wypych, Body image and cognitive restraint are risk factors for obesity in French adolescents, Eat. Weight Disord. Stud. Anorex. 18 (2013) 289-295, http://dx.doi.org/10.1007/s40519-013-0027-x.

[16] N. Vogels, D.L. Posthumus, E.C. Mariman, F. Bouwman, A.D. Kester, P. Rump, et al., Determinants of overweight in a cohort of Dutch children, Am. J. Clin. Nutr. 84 (2006) 717-724.

[17] C. Braet, L. Claus, L. Goossens, E. Moens, L. Van Vlierberghe, B. Soetens, Differences in eating style between overweight and normal-weight youngsters, J. Health Psychol. 13 (2008) 733-743, http://dx.doi.org/10.1177/1359105308093850.

[18] S. Carnell, L. Benson, K. Pryor, E. Driggin, Appetitive traits from infancy to adolescence: using behavioral and neural measures to investigate obesity risk, Physiol. Behav. 121 (2013) 79-88, http://dx.doi.org/10.1016/j.physbeh.2013.02.015.

[19] S. Chearskul, S. Pummoung, S. Vongsaiyat, P. Janyachailert, S. Phattharayuttawat, Thai version of Three-Factor Eating Questionnaire, Appetite 54 (2010) 410-413, http://dx.doi.org/10.1016/j.appet.2010.01.005.

[20] I. Rosnah, I. Noor Hassim, A.S. Shafizah, A systematic translation and cultural adaptation process for Three-Factor Eating Questionnaire (TFEQ-R21), Med. J. Malays. 68 (2013) 424-434

[21] A. Bazzocchi, D. Diano, F. Ponti, E. Salizzoni, U. Albisinni, G. Marchesini, et al., A 360 degree overview of body composition in healthy people: relationships among anthropometry, ultrasonography, and dual-energy x-ray absorptiometry, Nutrition 30 (2014) 696-701, http://dx.doi.org/10.1016/j.nut.2013.11.013.

[22] T.J. Cole, M.C. Bellizzi, K.M. Flegal, W.H. Dietz, Establishing a standard definition for child overweight and obesity worldwide: international survey, Br. Med. J. 320 (2000) 1240-1243, http://dx.doi.org/10.1136/bmj.320.7244.1240.

[23] H.M. Snoek, R.C. Engels, T. van Strien, R. Otten, Emotional, external and restrained eating behaviour and BMI trajectories in adolescence, Appetite 67 (2013) 81-87, http://dx.doi.org/10.1016/j.appet.2013.03.014

[24] L.C. Natacci, M. Ferreira Júnior, The three factor eating questionnaire-R21: translation and administration to Brazilian women, Rev. Nutr. 24 (2011) 383-394.

[25] R.M. Baños, A. Cebolla, E. Etchemendy, S. Felipe, P. Rasal, C. Botella, Validation of the Dutch Eating Behavior Questionnaire for Children (DEBQ-C) for use with Spanish children, Nutr. Hosp. 26 (2011) 890-898, http://dx.doi.org/10.1590/s021216112011000400032

[26] T. Ledoux, K. Watson, J. Baranowski, B.J. Tepper, T. Baranowski, Overeating styles and adiposity among multiethnic youth, Appetite 56 (2011) 71-77, http://dx.doi. org/10.1016/j.appet.2010.11.145.

[27] F. Rutters, A. Nieuwenhuizen, N. Vogels, F. Bouwman, E. Mariman, M. WesterterpPlantenga, Leptin-adiposity relationship changes, plus behavioral and parental factors, are involved in the development of body weight in a Dutch children cohort, Physiol. Behav. 93 (2008) 967-974, http://dx.doi.org/10.1016/j.physbeh.2007.12. 021.

[28] G.S. Goldfield, C. Moore, K. Henderson, A. Buchholz, N. Obeid, M.F. Flament, Body dissatisfaction, dietary restraint, depression, and weight status in adolescents, J. Sch. Health 80 (2010) 186-192. 
[29] A.M. Andrade, S.R. Coutinho, M.N. Silva, J. Mata, P.N. Vieira, C.S. Minderico, et al., The effect of physical activity on weight loss is mediated by eating self-regulation, Patient Educ. Couns. 79 (2010) 320-326, http://dx.doi.org/10.1016/j.pec.2010.01.006.

[30] E.J. Bryant, N.A. King, J.E. Blundell, Disinhibition: its effects on appetite and weight regulation, Obes. Rev. 9 (2008) 409-419, http://dx.doi.org/10.1111/j.1467-789X 2007.00426.x

[31] V. Drapeau, V. Provencher, S. Lemieux, J. Despres, C. Bouchard, A. Tremblay, Do 6-y changes in eating behaviors predict changes in body weight? Results from the Quebec Family Study, Int. J. Obes. 27 (2003) 808-814, http://dx.doi.org/10.1038/sj.ijo. 0802303.

[32] E.J. Bryant, K. Kiezebrink, N.A. King, J.E. Blundell, Interaction between disinhibition and restraint: implications for body weight and eating disturbance, Eat. Weight Disord. Stud. Anorex. 15 (2010) e43-e51.

[33] P. Morin, S. Turcotte, G. Perreault, Relationship between eating behaviors and physical activity among primary and secondary school students: results of a cross- sectional study, J. Sch. Health 83 (2013) 597-604, http://dx.doi.org/10.1111/josh. 12071.

[34] B. Gutin, Child obesity can be reduced with vigorous activity rather than restriction of energy intake, Obesity 16 (2008) 2193-2196, http://dx.doi.org/10.1038/oby. 2008.348.

[35] C. Ottevaere, I. Huybrechts, J. Benser, I. De Bourdeaudhuij, M. Cuenca-Garcia, J. Dallongeville, et al., Clustering patterns of physical activity, sedentary and dietary behavior among European adolescents: the HELENA study, BMC Public Health 11 (2011) 328, http://dx.doi.org/10.1186/1471-2458-11-328.

[36] C. Martins, L. Morgan, H. Truby, A review of the effects of exercise on appetite regulation: an obesity perspective, Int. J. Obes. 32 (2008) 1337-1347, http://dx.doi. org/10.1038/ijo.2008.98.

[37] N.P. Pronk, R.R. Wing, Physical activity and long-term maintenance of weight loss, Obes. Res. 2 (1994) 587-599. 